\title{
Establishment and evaluation of a reversible two-kidney, one-clip renovascular hypertensive rat model
}

\author{
LI-QIANG LI ${ }^{1}$, JIAN ZHANG ${ }^{1}$, RONG WANG ${ }^{2}$, JIAN-XIN LI $^{1}$ and YONG-QUAN GU ${ }^{1}$ \\ ${ }^{1}$ Department of Vascular Surgery, Xuan Wu Hospital and Institute of Vascular Surgery, Capital Medical University; \\ ${ }^{2}$ Central Laboratory, Xuan Wu Hospital, Capital Medical University, Beijing 100053, P.R. China
}

Received January 13, 2016; Accepted February 3, 2017

DOI: $10.3892 /$ etm.2017.4386

\begin{abstract}
The aim of the present study was to establish and evaluate a novel and reversible two-kidney, one-clip renovascular hypertensive rat model with a titanium vascular clip. A total of 40 male Sprague-Dawley rats were evenly and randomly divided into a sham-operated group, and 3, 7, 12 and 28D groups (namely removing the vascular clip in the renovascular hypertensive model after 3, 7, 12 and 28 days, respectively). The systolic blood pressure (SBP) and plasma renin activity (PRA) were measured, and color duplex imaging was conducted before placing the clips, as well as before and after removing them. After placing the vascular clips, SBP and PRA in the 3, 7, 12 and 28D groups were significantly increased (SBP: Sham-operated vs. 3D groups, $\mathrm{P}=0.020$; 3 vs. $7 \mathrm{D}$ groups, $\mathrm{P}=0.008 ; 7$ vs. $28 \mathrm{D}$ groups, $\mathrm{P}=0.019 ; 12$ vs. $28 \mathrm{D}$ groups, $\mathrm{P}=0.039$, and between other groups $\mathrm{P}<0.001$. PRA: 3 vs. $7 \mathrm{D}$ groups, $\mathrm{P}=0.001 ; 7$ vs. $12 \mathrm{D}$ groups, $\mathrm{P}=0.004 ; 12$ vs. 28D groups, $\mathrm{P}=0.040$, and between other groups, $\mathrm{P}<0.001$ ). After removing the clips, SBP were significantly reduced in the 3 and $7 \mathrm{D}$ groups $(\mathrm{P}=0.023,0.040,0.066$ and 0.314 in the 3 , 7, 12 and 28D groups, respectively), but were still significantly higher than that before placing clips in the 7, 12 and 28D groups $(\mathrm{P}=0.067, \mathrm{P}=0.005, \mathrm{P}<0.001$ and $\mathrm{P}<0.001$ in the $3,7,12$ and $28 \mathrm{D}$ groups, respectively). After removing the clips, PRA was significantly reduced in each group $(\mathrm{P}<0.001, \mathrm{P}<0.001$, $\mathrm{P}=0.012$ and $\mathrm{P}=0.049$ in 3, 7, 12 and 28D groups, respectively), but still higher than that before placing the clips $(\mathrm{P}<0.001$, $\mathrm{P}=0.001, \mathrm{P}=0.001$ and $\mathrm{P}=0.003$ in $3,7,12$ and $28 \mathrm{D}$ groups, respectively). Vascular imaging also indicates this model has a reversible property. In conclusion, a reversible renovascular hypertension rat model is feasible, and provides a basis for
\end{abstract}

Correspondence to: Dr Jian Zhang, Department of Vascular Surgery, Xuan Wu Hospital and Institute of Vascular Surgery, Capital Medical University, 45 Changchun Street, Beijing 100053 , P.R. China

E-mail: zhangjiandoctor@126.com

Key words: renal artery stenosis, renin-angiotensin-aldosterone system, renovascular hypertension, rat model, plasma renin activity research on clinical ischemic nephropathy and renal artery revascularization.

\section{Introduction}

Renovascular hypertension is clinically important. Previous high-quality studies suggest that interventions, including stenting for renovascular hypertension, are not as effective long term compared to medication $(1,2)$. In addition, the vast majority of cases of renovascular hypertension are atherosclerotic, and the disease is systemic and complex. However, these studies have been criticized for several reasons, including the inclusion of a large number of cases with minor vascular occlusive disease, numerous complications, poor technique and inexperienced operators (3). Therefore, the usefulness of endovascular therapy for reducing blood pressure and preventing renal and cardiovascular events remains uncertain. Furthermore, the development of precise methods to identify critically severe renovascular disease, such as plasma biomarkers, will be essential to bring the advantages of revascularization to those most likely to benefit. Experimental models of hypertension, including the two-kidney, one-clip Goldblatt model have been clearly described in basic research on hypertension (4), cardiovascular (5) and kidney disease (6). In the Goldblatt model of hypertension, the kidney is considered to be a vital organ in the pathogenesis of renovascular hypertension, as it is the origin of the pressor rennin-angiotensin system and controls water and sodium balance (7). Blood flow is decreased in the clipped kidney contributing to ischemia, and the non-clipped kidney is characterized by increased shear stress (8). The present study hypothesized that a novel model with a reversible property could simulate renal artery revascularization, which means that the blood flow of the renal artery could return to normal following removal of renal artery stenosis. Although a local clip in this renovascular hypertensive model is unlikely to represent the same conditions as in a clinical situation, we hope that this model provides a basis for further research on changes in biomarkers of renal fibrosis, including neutrophil gelatinase-associated lipocalin, serum creatinine and cystatin $\mathrm{C}$. In addition, the aim of the present study is to identify a plasma biomarker with satisfactory specificity and sensibility in order to instruct the prognosis of endovascular therapy, indicating whether patients' hypertension can be relieved following renal artery revascularization. 


\section{Materials and methods}

Animals. A total of 40 specific pathogen-free male Sprague-Dawley rats (Vital River Laboratory Animal Technology Co., Ltd., Beijing, China) were housed individually with constant humidity and temperature $\left(25^{\circ} \mathrm{C}\right)$. Rats were acclimatized for at least one week and had unrestricted water intake under such conditions before the start of the experiments. Furthermore, the experiments were conducted in accordance with the National Institutes of Health guide for the care and use of Laboratory animals. In addition, all efforts were made to relieve rats' suffering and to reduce the number of animals used. The animal use protocol has been approved by the Institutional Animal Care and Use Committee of Capital Medical University (Beijing, China).

Surgical procedure. Rats (weight, 350-400 g; age, 8-10 weeks) were evenly and randomly divided into sham-operated, 3,7 , 12 and 28D groups. All rats were anesthetized by a peritoneal injection of $0.3 \mathrm{ml} / 100 \mathrm{~g} 10 \%$ chloral hydrate (Jiang Lai Biotech., Beijing, China). After being shaved, the abdominal wall was coated with povidone-iodine (Yuande Biomeidical Engineering Co., Beijing China) and 70\% alcohol (Jiang Lai Biotech.). The left renal hilum was revealed through a flank abdominal incision (Fig. 1A), and the renal artery and vein were carefully isolated by blunt dissection. In each of the rats in the 3,7,12 and 28D groups an insulin needle tip whose outer diameter was $0.23 \mathrm{~mm}$ was used in order to prevent vessel compression during clip placement. In addition, a titanium vascular clip was gently placed around the left renal artery (Fig. 1B and C). The needle tip was then carefully removed (Fig. 1D). Rats in sham-operated group underwent the same surgical procedure, except for the application of the vascular clip. Abdominal contents were carefully returned to their original location, and the abdominal wall and skin was sutured. In addition, rats in the 3,7,12 and 28D groups received another operation after 3, 7, 12 and 28 days, respectively. The left renal artery was exposed via back incision, carefully isolated and the vascular clip was removed (unclipping, UC). After each operation, intramuscular injection of 50,000 units/100 g penicillin (North China Pharmaceutical Co., Ltd., Shijiazhuang, China) was used for three days. All rats were then observed for $1 \mathrm{~h}$ following surgery, then individually housed and allowed free access to food and water. The sham-operated group also underwent these procedures but without a clip compared to the operation group.

Systolic blood pressure (SBP). SBP of every unanesthetized rat was measured before placing clips and before UC by means of the tail-cuff method. SBP was measured three times, and the average value was then obtained. In addition, SBP of rats in 3 , 7, 12 and 28D groups were measured after UC for 3, 7, 12 and 28 days, respectively. Prior to the blood pressure measurement, the rats were warmed to $35^{\circ} \mathrm{C}$ in a cupboard for $10 \mathrm{~min}$.

Color duplex imaging. Immediately posterior to the SBP measurement of all the timepoints, the rats were anesthetized by $0.3 \mathrm{ml} / 100 \mathrm{~g} \mathrm{10 \%}$ chloral hydrate (Jiang Lai Biotech.) and sonography was performed with a Vevo 2100 high-frequency, high-resolution ultrasound system (Fujifilm VisualSonics,
Inc., Toronto, ON, Canada) with a transducer frequency of 12.5-15 MHz. Color Doppler Mode was selected for detection of blood vessels including flow directional information and peak systolic velocity (PSV) at the place of the vascular clip and aorta at the origin of the renal artery.

Plasma renin activity (PRA). Immediately following undergoing color duplex examination of each time, the rat tail was disinfected, and was then cut with operation scissors. Blood flowed out the tail end and $1 \mathrm{ml}$ was collected in $\mathrm{K} 3$ EDTA tubes (North Institute of Biological Technology, Beijing, China). After centrifugation and storage at $4^{\circ} \mathrm{C}$, the EDTA-plasma samples were analyzed using an iodine $\left({ }^{125} \mathrm{I}\right)$ angiotensin I radioimmunoassay kit (North Institute of Biological Technology). PRA was then determined by comparing the samples to a standard curve. At the end of the study period, the rats were sacrificed by carbon dioxide asphyxiation.

Statistical analysis. Values are expressed as the mean \pm standard error of the mean. All data were analyzed using SPSS 22.0 software (IBM SPSS, Armonk, NY, USA). Differences in placing and removing clips in every group were assessed by analysis of variance in a randomized block design. Where a significant difference was identified, the groups were compared by Student's t-test. $\mathrm{P}<0.05$ was used to indicate a statistically significant difference.

\section{Results}

SBP. As summarized in Fig. 2, after placing the vascular clips, SBP in the 3, 7, 12 and 28D groups significantly increased to $125 \pm 13,143 \pm 13,174 \pm 14$ and $160 \pm 11 \mathrm{mmHg}$, respectively (sham-operated vs. 3D group, $\mathrm{P}=0.020 ; 3$ vs. 7D group, $\mathrm{P}=0.008 ; 7$ vs. $28 \mathrm{D}$ group, $\mathrm{P}=0.019 ; 12$ vs. $28 \mathrm{D}$ group, $\mathrm{P}=0.039$ and between other groups $\mathrm{P}<0.001$ ). Following $\mathrm{UC}, \mathrm{SBP}$ in the 3 and 7D groups were significantly reduced to $109 \pm 13$ and $129 \pm 11 \mathrm{mmHg}$ (in 3, 7, 12 and 28D groups, $\mathrm{P}=0.023,0.040$, 0.066 and 0.314 , respectively). SBP after UC were significantly higher than that before placing the clips in the 7,12 and 28D groups (in 3, 7, 12 and $28 \mathrm{D}$ groups, $\mathrm{P}=0.067, \mathrm{P}=0.005, \mathrm{P}<0.001$ and $\mathrm{P}<0.001$, respectively).

PRA. As summarized in Fig. 3, after placing the vascular clips, the PRA in 3, 7, 12 and 28D groups increased significantly to $18.74 \pm 2.68,14.43 \pm 2.56,10.96 \pm 2.49$ and $8.53 \pm 1.62 \mathrm{ng} / \mathrm{ml}$, respectively ( 3 vs. $7 \mathrm{D}$ group, $\mathrm{P}=0.001 ; 7$ vs. $12 \mathrm{D}$ group, $\mathrm{P}=0.004$; 12 vs. $28 \mathrm{D}$ group, $\mathrm{P}=0.040$, and between other groups $\mathrm{P}<0.001$ ). After UC, the PRA in each group was significantly reduced to $10.46 \pm 2.49,8.47 \pm 2.60,7.89 \pm 2.13$ and $6.77 \pm 1.48 \mathrm{ng} / \mathrm{ml}$, respectively (in the $3,7,12$ and $28 \mathrm{D}$ group, $\mathrm{P}<0.001, \mathrm{P}<0.001$, $\mathrm{P}=0.012$ and $\mathrm{P}=0.049$, respectively), but remained higher than that before placing the clips (in the 3, 7, 12 and 28D groups, $\mathrm{P}<0.001, \mathrm{P}=0.001, \mathrm{P}=0.001$ and $\mathrm{P}=0.003$, respectively).

Color duplex imaging. PSV at the location of the vascular clip and the aorta at the origin of the renal artery were obtained, and the resulting renal-aortic ratio (RAR) $>3.5$ indicated a hemodynamically significant renal artery stenosis $(60-99 \%)(9,10)$. Before placing clips, the PSV values at 

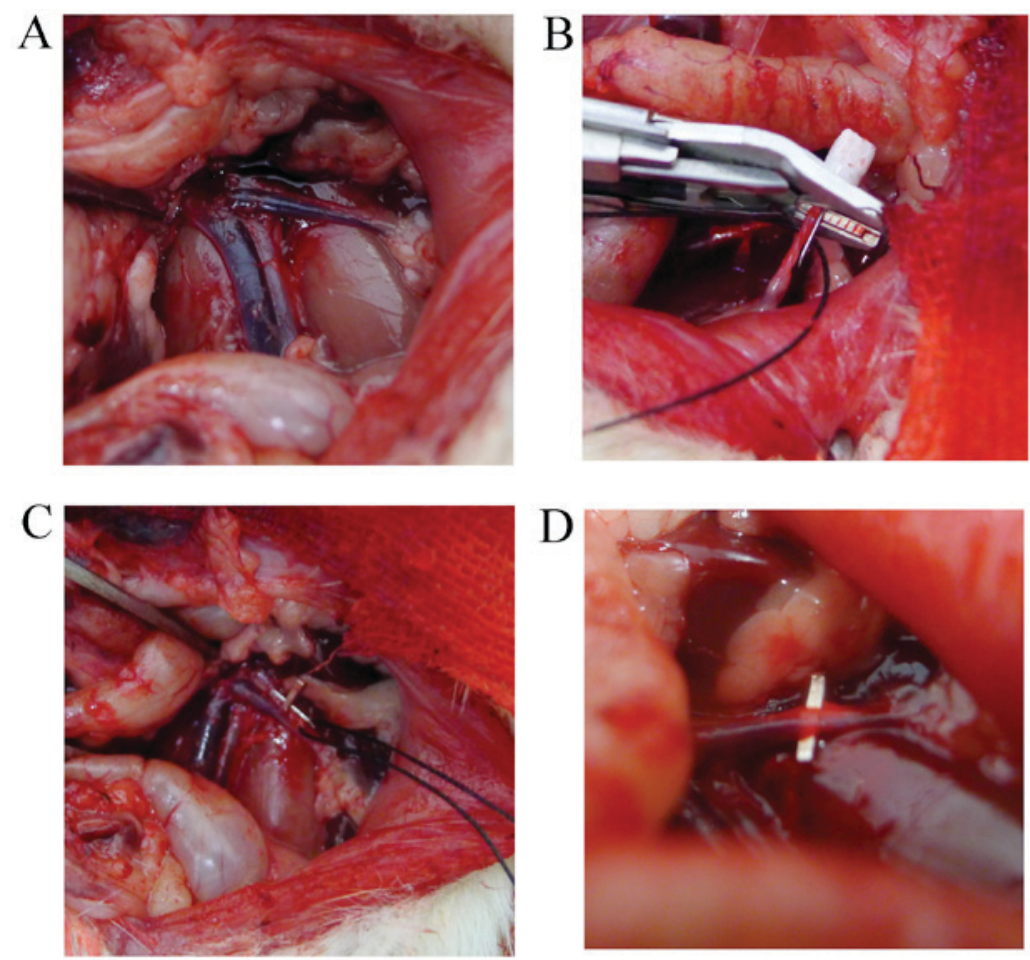

Figure 1. A renovascular hypertensive model was established using the $2 \mathrm{~K} 1 \mathrm{C}$ method. (A) View through a flank abdominal incision where the left renal hilum was revealed. (B) View of the renal artery and vein that were carefully isolated by blunt dissection. (C) A titanium vascular clip is shown that was successfully placed on the left renal artery, with the aid of an insulin needle tip whose outer diameter was $0.23 \mathrm{~mm}$. (D) Image showing that the insulin needle tip was carefully removed.

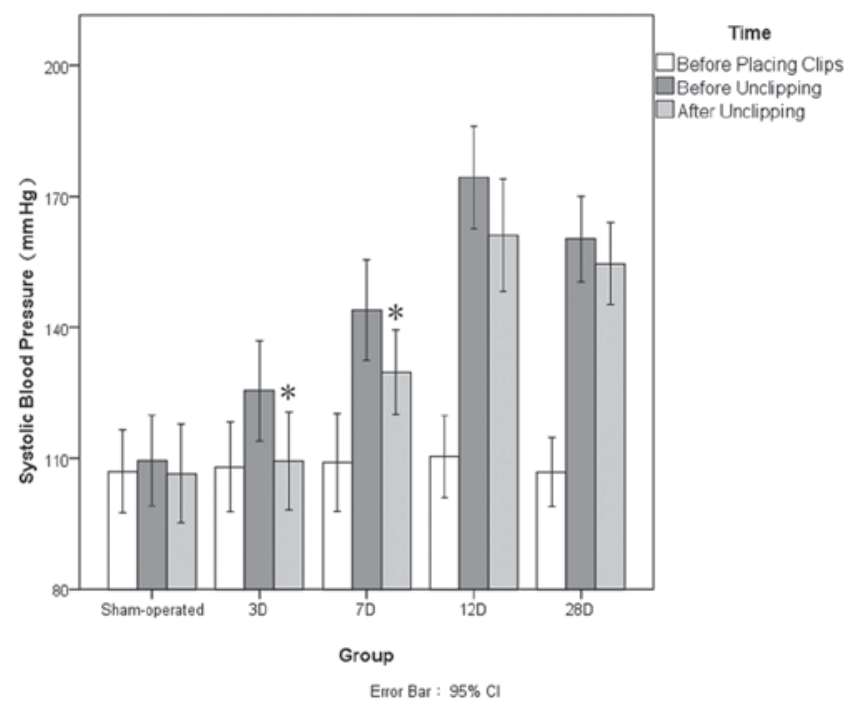

Figure 2. Vascular clipping and unclipping resulted in systolic blood pressure changes. After placing clips, systolic blood pressure in the 3,7,12 and 28D group significantly increased. In addition, after removing the clips, SBP in the 3 and 7D group were significantly reduced. Systolic blood pressure after unclipping were significantly higher than that before placing clips in the 7, 12 and $28 \mathrm{D}$ groups. ${ }^{*} \mathrm{P}<0.05$ after unclipping vs. befor unclipping.

the middle section of the renal artery and at the aorta were $390.4 \pm 96.9$ and $413.7 \pm 77.1 \mathrm{~mm} / \mathrm{sec}\left(\mathrm{PSV}_{\text {renal artery }}\right.$ vs. $\mathrm{PSV}_{\text {aorta }}$, $\mathrm{P}=0.947$ ) with a RAR of every subject $<1.5: 1$. After placing the clips, the PSV near the location of vascular clip and aorta confirmed renal artery stenosis directly on the basis of an increase in $\mathrm{PSV}_{\text {renal artery }}$ of $1,576.4 \pm 120.5 \mathrm{~mm} / \mathrm{sec}$ and $\mathrm{PSV}_{\text {aorta }}$

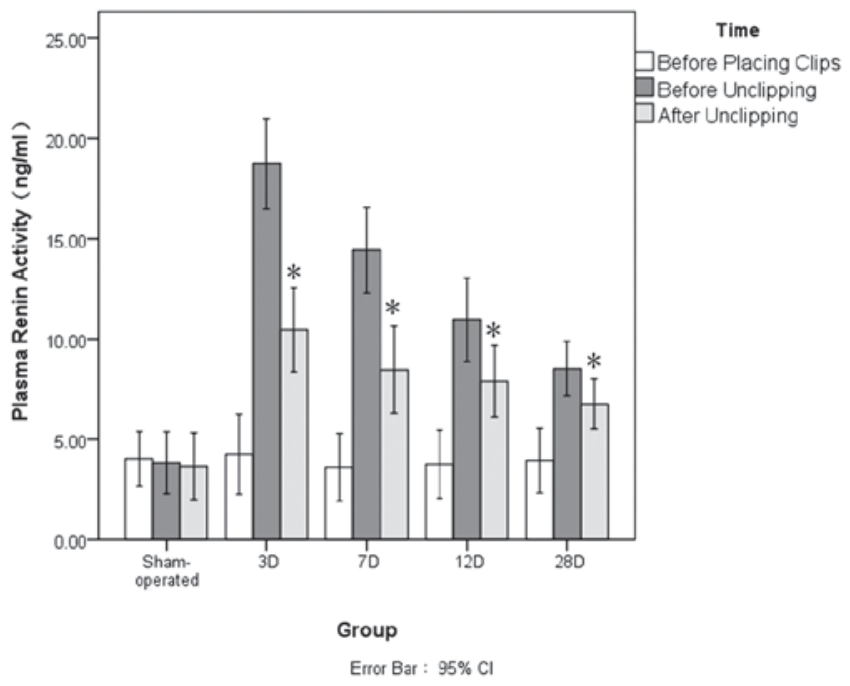

Figure 3. Vascular clipping and unclipping resulted in plasma renin activity changes. After placing the clips, plasma renin activity in 3, 7, 12 and 28D group significantly increased. After unclipping, plasma renin activity in each group were significantly reduced but was still higher than that before placing the clips. ${ }^{*} \mathrm{P}<0.05$ after unclipping vs. before unclipping.

of $375.2 \pm 86.3 \mathrm{~mm} / \mathrm{sec}\left(\mathrm{PSV}_{\text {renal artery }}\right.$ vs. $\left.\mathrm{PSV}_{\text {aorta }}, \mathrm{P}<0.001\right)$, and with RAR of every subject $>3.5$ (Fig. 4). Following UC, Doppler waveforms and PSV had a normal recovery with PSV $\mathrm{V}_{\text {renal artery }}$ of $426.0 \pm 79.8 \mathrm{~mm} / \mathrm{sec}$ and $\mathrm{PSV}_{\text {aorta }}$ of $408.2 \pm 76.3 \mathrm{~mm} / \mathrm{sec}$ $\left(\mathrm{PSV}_{\text {renal artery }}\right.$ vs. $\mathrm{PSV}$ aorta, $\mathrm{P}=0.892$ ), which was the same as that before placing vascular clips with RAR of every subject $<1.5: 1$. 

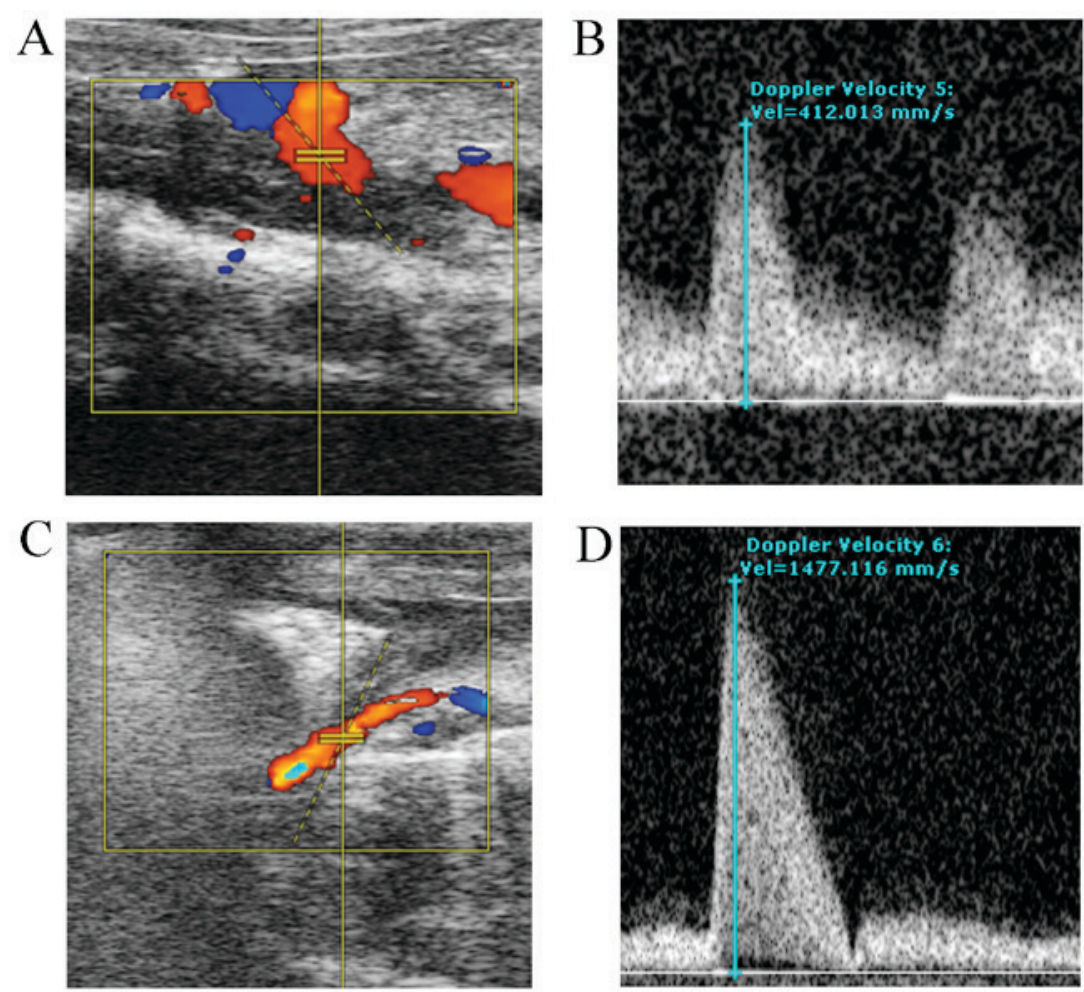

Figure 4. Waveforms and peak systolic velocity changes in the $2 \mathrm{~K} 1 \mathrm{C}$ model observed by color duplex imaging. (A) Image from color duplex imaging. Color duplex imaging was performed at the aorta near the site of the left renal artery. (B) Waveforms and peak systolic velocity at the aorta are shown that were obtained near the site of the left renal artery. (C) Image from color duplex imaging. Color duplex imaging was performed at the vascular clip site of the left renal artery. (D) Waveforms and peak systolic velocity are shown that were obtained at the vascular clip site of the left renal artery.

\section{Discussion}

Renal artery stenosis (RAS), which causes narrowing of the renal artery or its main branches, is produced by a heterogeneous group of conditions, including atherosclerosis, fibromuscular dysplasia, congenital bands, extrinsic compression, vasculitis, neurofibromatosis and radiation (11). Renovascular hypertension refers to the rise in arterial pressure led by reduced renal artery perfusion, as the most common secondary forms of hypertension. In addition, reduced kidney perfusion can also lead to ischemic nephropathy, manifesting to loss of kidney size and function, when RAS is severe and prolonged (12). Due to these conditions the benefit from vascular intervention remains a controversial topic (13), and thus establishing an animal model that simulates renal artery revascularization is required.

In 1934, Goldblatt et al (14) established the association between renal artery and sustained hypertension in dogs by placing arterial occlusive clamps. The physiopathological mechanism of the sustained hypertension is complex and multifactorial, and its basis is the activation of the renin angiotensin aldosterone system (RAAS). Reduced perfusion to the kidney contributes to the release of renin from juxtaglomerular cells to the afferent arteriole $(15,16)$. A cascade reaction amplified the signal to produce both local and systematic angiotensin II, whose biochemical reactions are complex. Angiotensin II raises arterial pressure by direct vascular effects and by changing renal sodium homeostasis, in addition to having wide effects on other pressure systems, fibrosis and remodeling $(17,18)$. The one-kidney, one-clip
(1K1C), two-kidney, one-clip (2K1C) and two-kidney, two-clip (2K2C) are methods used to induce renovascular hypertension (19). In rabbits (20) and rats (21), 2K1C induces a chronic and gradual rise in the arterial pressure, which peaks after two weeks and decreases subsequently in 10-20\% of the subjects. In general, rats develop hypertension more easily than rabbits, and become the primary choice to establishing a $2 \mathrm{~K} 1 \mathrm{C}$ renovascular hypertensive model.

However, perhaps due to the design flaws in traditionally used silver clips, early studies on establishing a $2 \mathrm{~K} 1 \mathrm{C}$ renovascular hypertensive model often concluded in low success rates of 40-60\% (22-24). The gap widths of traditionally designed silver clips cannot be well maintained during handling or these clips can also be dislodged from the renal artery following placement. Furthermore, silver is malleable and easily reshaped. However, this ductile nature may lead to the unreliability of the U-shape clip, thereby resulting in different changes in the renal artery lumen diameters. In addition, if there are silver dioxides on the surface of the clip during sterilization and handling, the clip could cause perivascular inflammation, intimal proliferation and tissue granulation, which may further alter the renal artery diameter, particularly in chronic phases (25). Furthermore, Kraft et al (26) illustrated that silver or stainless steel implants may elicit in leukocyte extravasation and venular dilation to some degree. In an attempt to solve the problems mentioned above, a titanium vascular clip was used in the 2K1C model. Chelko et al (27) reported that the application of clips with a gap of width of $0.23 \mathrm{~mm}$ could induce reliable and consistent hypertension in rats. Therefore, the needle tip of insulin with a $0.23 \mathrm{~mm}$ outer 
diameter was used to measure the residual diameter of the left renal artery in the $2 \mathrm{~K} 1 \mathrm{C}$ model.

Following placement of the clip, the factor maintaining the subsequent rise in arterial pressure is characterized by an increased activity of the RAAS (28). However, controversy surrounds the role of the sympathetic nervous system (SNS) in the maintenance of $2 \mathrm{~K} 1 \mathrm{C}$ hypertension. In a six-week observation, the arterial pressure of $2 \mathrm{~K} 1 \mathrm{C}$ was almost reduced to normal levels by administration of the angiotensin receptor blocker (ARB). Furthermore, arterial pressure was not significantly affected by sympathetic blockade, and the combination of sympathetic blockade and ARB were not more effective than ARB alone (29). Therefore, the influence of SNS on $2 \mathrm{~K} 1 \mathrm{C}$ hypertension in this phase is negligible. $\mathrm{UC}$ in the $2 \mathrm{~K} 1 \mathrm{C}$ model returns arterial pressure to almost normotensive levels within a few hours. It has been suggested that the reduction in arterial pressure after UC is caused by the release of a putative renal medullary depressor hormone (30). Furthermore, UC or removal of the ischemic kidney resulted in similar reductions in arterial pressure, indicating that the reduction in arterial pressure observed after UC is mainly attributed to elimination of angiotensin II secretion from the ischemic kidney and reduced plasma concentration of renin following the normalization of renal perfusion pressure. No clear link between UC and the decreased activity of SNS observed in the $2 \mathrm{~K} 1 \mathrm{C}$ model was identified. In summary, both maintenance and reversal of hypertension in a $2 \mathrm{~K} 1 \mathrm{C}$ hypertensive model are controlled by the RAAS (29).

In a previous study and as mentioned above, the blood pressure after UC declined in a few hours (30). However, none of the data of long time observation has been previously reported. In the present study, SBP increased and peaked in the 12D group after placing titanium vascular clips. Following UC, SBP in the 3 and 7D groups were significantly reduced whereas in the 12 and 28D groups SBP did not decline. Moreover, SBP in 7, 12 and 28D groups after removing clips were significantly higher than normal. This result indicates that renal ischemia injury was irreversible in the 12 and 28D groups, and it is likely that this irreversible change happened in 7-12D group. The present study indicates that the placement of a titanium vascular clip could establish renal artery stenosis and induce renovascular hypertension. The removal of the clip could eliminate renal artery stenosis and lower the blood pressure in the early phase. However, despite the patency of renal artery, the SBP cannot return to normal in chronic phases. It was hypothesized that the reason that renal hypertension was dominant instead of renovascular hypertension at some time point was due to the renal fibrosis as the prolonged renal ischemia time (31).

However, arterial pressure may be influenced by numerous factors, including animal age, clip type, postoperative stress, measuring time, environmental changes and diet (32). In order to supply more evidence to verify the fact that stenosis exists after the placement of a clip and disappears after the removal of the clip, PRA was measured soon after the measurement of SBP each time.

The PRA change in each group of the rat models studied is shown in the graph in Fig. 3. Although the degree of change varied, it was significant between each group after placing clips for $3,7,12$ and 28 days, with the highest value observed in the $12 \mathrm{D}$ group. In each group, PRA declined significantly after UC, but was still significantly higher than that prior to the surgery. Hypertension in the 2K1C model may be influenced by renin released from the stenotic kidney. Kidney-borne renin, as the key regulator of RAAS, plays an essential part in extracellular fluid volume, sodium and blood pressure homeostasis (16). Renin release is suppressed and sodium excretion is increased from the contralateral kidney, which tends to reduce blood pressure (33-35). As follows, stenotic renal perfusion pressure is decreased and renin is again released, which leads to elevated blood pressure (36-38). Several reasons may be responsible for the subsequent decline of systemic PRA $(39,40)$. If the increase in systemic pressure restores the perfusion pressure of the stenotic kidney, as in slight or moderate renal artery stenosis, PRA and angiotensin II can be sustained with relatively low levels or even return to normal levels $(41,42)$. However, in severe renal artery stenosis, these series of the reaction cannot be cycled, which may result in volume depletion and renal failure. Due to a wide range of severity of stenosis, coexistent morbidities, age, posture and sodium intake, PRA and other hormones have a considerable variability in PRA. This partly explains the unpredictability of the blood pressure response to vascular intervention by measuring a single pathway in humans (43).

Therefore, prior to placing a vascular clip as well as before and after UC, every rat received color duplex imaging examination. To date, there is no criterion to diagnose renal artery stenosis in rats. In addition, rats have a different circulation feature, which is that the normal PSV at each site of renal vascular is approximately $400 \mathrm{~mm} / \mathrm{sec}$. Thus, it has been proposed that the PSV in the aorta may be associated to that at the origin of the renal artery. Therefore, the resulting renal-aortic ratio (RAR) $>3.5$ indicated significant hemodynamic renal artery stenosis (60-99\%). The RAR was found to have a surprisingly high sensitivity of $83-100 \%$ and a specificity of $73-97 \%(9,10)$. Furthermore, following removal of the clips, PSV in the sonography at each site returned normal. In conclusion, to evaluate the recovery of blood flow in the renal artery after removing the clips, SBP in early phase, PRA measurements and image indications of renal artery stenosis indicate reversible characteristics were exhibited and levels were returned to normal. The results proved that after removal of the clip, the blood pressure and PRA significantly decreased in the $2 \mathrm{~K} 1 \mathrm{C}$ rat model. In addition, a reversible renovascular hypertensive rat model is feasible and plausible. However, SBP in a later phase has no such reversible properties. We hypothesized that the main cause is that renovascular hypertension was replaced by renal hypertension as the process of renal fibrosis was induced by renal ischemia. Establishment of this model provides the basis for further research on changes in biomarkers of renal fibrosis, including neutrophil gelatinase-associated lipocalin, serum creatinine, and cystatin $\mathrm{C}$ when the vascular clip is placed and removed. Finally, we hope that a plasma biomarker with satisfactory specificity and sensibility can be found to instruct the prognosis of renovascular hypertension and ischemic nephropathy. In other words, a specific and sensitive biomarker is required in order to assess whether hypertension could be relieved following renal artery revascularization. 


\section{References}

1. Henry M, Benjelloun A, Henry I, Polydorou A and Hugel M: Renal angioplasty and stenting: Is it still indicated after ASTRAL and STAR studies? J Cardiovasc Surg (Torino) 51: 701-720, 2010

2. Gosse P: After STAR and ASTRAL, let's go back on earth!. J Radiol 92: 186-187, 2011 (In French).

3. Cooper CJ, Murphy TP, Cutlip DE, Jamerson K, Henrich W, Reid DM, Cohen DJ, Matsumoto AH, Steffes M, Jaff MR, et al: Stenting and medical therapy for atherosclerotic renal-artery stenosis. N Engl J Med 370: 13-22, 2014.

4. Bartosiewicz J, Kaminski T, Pawlak K, Karbowska M, Tankiewicz-Kwedlo A and Pawlak D: The activation of the kynurenine pathway in a rat model with renovascular hypertension. Exp Biol Med (Maywood): Jan 1, 2017 (Epub ahead of print).

5. Soltani Hekmat A, Javanmardi K, Kouhpayeh A, Baharamali E and Farjam M: Differences in cardiovascular responses to alamandine in two-kidney, one clip hypertensive and normotensive rats. Circ J: Feb 24, 2017 (Epub ahead of print).

6. Vethe H, Finne K, Skogstrand T, Vaudel M, Vikse BE, Hultström M, Placier S, Scherer A, Tenstad O and Marti HP: Distinct protein signature of hypertension-induced damage in the renal proteome of the two-kidney, one-clip rat model. J Hypertens 33: 126-135, 2015.

7. Akabane S, Natsume T, Matsushima Y, Deguchi F, Kuramochi M and Ito $\mathrm{K}$ : Alterations in renal $\mathrm{Na}+\mathrm{K}+\mathrm{ATPase}$ activity and $[3 \mathrm{H}]$ ouabain binding in Goldblatt hypertensive rabbits. J Hypertens 3 : 469-474, 1985.

8. Hocher B, George I, Diekmann F, Zart R, Rebstock J, Schwarz A, Thöne-Reineke C, Neumayer HH and Bauer C: ETA receptor blockade induces fibrosis of the clipped kidney in two-kidney-one-clip renovascular hypertensive rats. J Hypertens 18: 1807-1814, 2000.

9. Frauchiger B, Bock A, Eichlisberger R, Landmann J, Thiel G, Mihatsch MJ and Jäger K: The value of different resistance parameters in distinguishing biopsy-proved dysfunction of renal-allografts. Nephrol Dial Transplant 10: 527-532, 1995.

10. Miralles M, Cairols M, Cotillas J, Giménez A and Santiso A: Value of Doppler parameters in the diagnosis of renal artery stenosis. J Vasc Surg 23: 428-435, 1996.

11. Lao D, Parasher PS, Cho KC and Yeghiazarians Y: Atherosclerotic renal artery stenosis-diagnosis and treatment. Mayo Clinic Proc 86: 649-657, 2011.

12. Shanley PF: The pathology of chronic renal ischemia. Semin Nephrol 16: 21-32, 1996.

13. Textor SC: Issues in renovascular disease and ischemic nephropathy: Beyond ASTRAL. Curr Opin Nephrol Hypertens 20: 139-145, 2011.

14. Goldblatt H, Lynch J, Hanzal RF and Summerville WW: Studies on experimental hypertension: I. The production of persistent elevation of systolic blood pressure by means of renal ischemia J Exp Med 59: 347-379, 1934

15. Schweda F and Kurtz A: Cellular mechanism of renin release. Acta physiol Scand 181: 383-390, 2004.

16. Kurtz A: Renin Release: Sites, Mechanisms, and Control. Annu Rev Physiol 73: 377-399, 2011.

17. Navar LG, Harrison-Bernard LM, Imig JD, Wang CT, Cervenka L and Mitchell KD: Intrarenal angiotensin II generation and renal effects of AT1 receptor blockade. J Am Soc Nephrol 10 (Suppl 12): S266-S272, 1999

18. Seeliger E, Wronski T, Ladwig M, Dobrowolski L, Vogel T, Godes M, Persson PB and Flemming B: The renin-angiotensin system and the third mechanism of renal blood flow autoregulation. Am J Physiol Renal Physiol 296: F1334-F1345, 2009.

19. Lee HB and Blaufox MD: Technetium-99m MAG-3 clearances after captopril in experimental renovascular hypertension. J Nucl Med 30: 666-671, 1989.

20. Fujii J, Kurihara H, Yamaguchi H, Terasawa F and Murata K: A persistent hypertension due to unilateral renal-artery constriction in the rabbit. Jpn Circ J 31: 1197-1200, 1967.

21. Leenen FH and de Jong W: A solid silver clip for induction of predictable levels of renal hypertension in the rat. J Appl Physiol 31: 142-144, 1971.
22. Tobian L, Janecek $\mathbf{J}$ and Tomboulian A: The effect of a high sodium intake on the development of permanent nephrosclerotic hypertension; effect of nephrosclerotic hypertension of the granularity of the juxtaglomerular cells. J Lab Clin Med 53: 842-848, 1959

23. Dussaule JC, Michel JB, Auzan C, Schwartz K, Corvol P and Menard J: Effect of antihypertensive treatment on the left ventricular isomyosin profile in one-clip, two kidney hypertensive rats. J Pharmacol Exp Ther 236: 512-518, 1986.

24. Helle F, Vågnes ØB and Iversen BM: Angiotensin II-induced calcium signaling in the afferent arteriole from rats with two-kidney, one-clip hypertension. Am J Physiol Renal Physiol 291: F140-F147, 2006.

25. Jackson WF and Duling BR: Toxic effects of silver-silver chloride electrodes on vascular smooth muscle. Circ Res 53: 105-108, 1983

26. Kraft CN, Hansis M, Arens S, Menger MD and Vollmar B: Striated muscle microvascular response to silver implants: A comparative in vivo study with titanium and stainless steel. J Biomed Mater Res 49: 192-199, 2000.

27. Chelko SP, Schmiedt CW, Lewis TH, Lewis SJ and Robertson TP A novel vascular clip design for the reliable induction of 2-kidney, 1-clip hypertension in the rat. J Appl Physiol (1985) 112: 362-366, 2012.

28. Martinez-Maldonado M: Pathophysiology of renovascular hypertension. Hypertension 17: 707-719, 1991.

29. Nystrom HC, Jia J, Johansson M, Lambert G and Bergström G: Neurohormonal influences on maintenance and reversal of two-kidney one-clip renal hypertension. Acta Physiol Scand 175: 245-251, 2002

30. Bergström G, Göthberg G, Karlström G and Rudenstam J: Renal medullary blood flow and renal medullary antihypertensive mechanisms. Clin Exp Hypertens 20: 1-26, 1998.

31. Cui R, Chen X, Peng L, Ma J, Zhu D, Li T, Wei Q and Li B: Multiple mechanisms in renal artery stenosis-induced renal interstitial fibrosis. Nephron Exp Nephrol 128: 57-66, 2014.

32. Möhring J, Möhring B, Näumann HJ, Philippi A, Homsy E, Orth H, Dauda G and Kazda S: Salt and water balance and renin activity in renal hypertension of rats. Am J Physiol 228: $1847-1855,1975$

33. Simon G and Coleman CC: Captopril-stimulated renal vein renin measurements in the diagnosis of atherosclerotic renovascular hypertension. Am J Hypertens 7: 1-6, 1994.

34. Della Bruna R, Bernhard I, Gess B, Schricker K and Kurtz A: Renin gene and angiotensin II AT1 receptor gene expression in the kidneys of normal and of two-kidney/one-clip rats. Pflugers Arch 430: 265-272, 1995

35. Stella A and Zanchetti A: Interactions between the sympathetic nervous system and the kidney: Experimental observations. J Hypertens Suppl 3: S19-S25, 1985.

36. Romero JC and Knox FG: Mechanisms underlying pressure-related natriuresis: The role of the renin-angiotensin and prostaglandin systems. State of the art lecture. Hypertension 11: 724-738, 1988

37. Rodriguez-Porcel M, Lerman LO, Sheedy PF II and Romero JC: Perfusion pressure dependency of in vivo renal tubular dynamics. Am J Physiol 273: F667-F673, 1997.

38. Rodriguez-Porcel M, Krier JD, Lerman A, Sheedy PF II, Romero JC, Napoli C and Lerman LO: Combination of hypercholesterolemia and hypertension augments renal function abnormalities. Hypertension 37: 774-780, 2001

39. Lerman LO, Schwartz RS, Grande JP, Sheedy PF and Romero JC: Noninvasive evaluation of a novel swine model of renal artery stenosis. J Am Soc Nephrol 10: 1455-1465, 1999.

40. Lerman LO, Nath KA, Rodriguez-Porcel M, Krier JD, Schwartz RS, Napoli C and Romero JC: Increased oxidative stress in experimental renovascular hypertension. Hypertension 37: 541-546, 2001.

41. Romero JC, Feldstein AE, Rodriguez-Porcel MG and Cases-Amenos A: New insights into the pathophysiology of renovascular hypertension. Mayo Clin Proc 72: 251-260, 1997.

42. Romero JC and Reckelhoff JF: State-of-the-Art lecture. Role of angiotensin and oxidative stress in essential hypertension. Hypertension 34: 943-949, 1999.

43. Safian RD and Textor SC: Renal-artery stenosis. N Engl J Med 344: 431-442, 2001. 